\title{
Hierarchical collagen-hydroxyapatite nanostructures designed through layer-by-layer assembly of crystal-decorated fibrils
}

\section{Supporting Information}

Elodie Colaço a, Dalil Brouri ${ }^{b}$, Nesrine Aissaoui ${ }^{c}$, Pauline Cornette ${ }^{b}$, Vincent Dupres ${ }^{d}$, Rute

F. Domingos ${ }^{\mathrm{e}}$, Jean-François Lambert ${ }^{\mathrm{b}}$, Emmanuel Maisonhaute ${ }^{\mathrm{f}}$, Karim El Kirat a, Jessem

$$
\text { Landoulsi }{ }^{\text {a, }} \text { * }
$$

\section{Table of contents}

1. Properties of Hap NPs

2. Raman

3. Morphology of Hap NPs in aqueous conditions

4. Hap - Col interaction in solution

5. LbL assembly of collagen-based multilayers

6. LbL assembly without renewing Hap - Col suspension

7. Hap - Col composite in $\mathrm{NaCl}$ solution

8. References 


\section{Properties of Hap NPs}
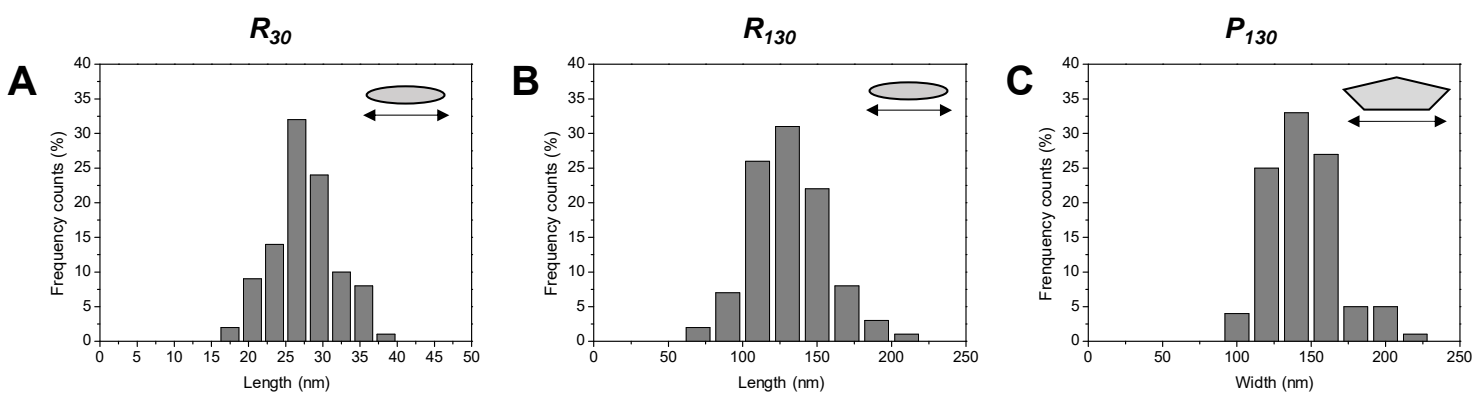

Figure S1. Size distribution of Hap NPs: (A) $R_{30}$, (B) $R_{130}$ and (C) $P_{130}$ NPs. The size distributions were plotted on the basis of 100 measurements from TEM images. Gaussian fits yield mean length values of $27.3 \pm 3.66$ and $128.7 \pm 23.5$ for $R_{30}, R_{130}$ (rods), respectively, and mean width value of $141.2 \pm 22.0 \mathrm{~nm}$ for $P_{130}$ (platelets) NPs. These yield polydispersity index (PDI) values of $0.16,0.21$ and 0.18 , respectively.
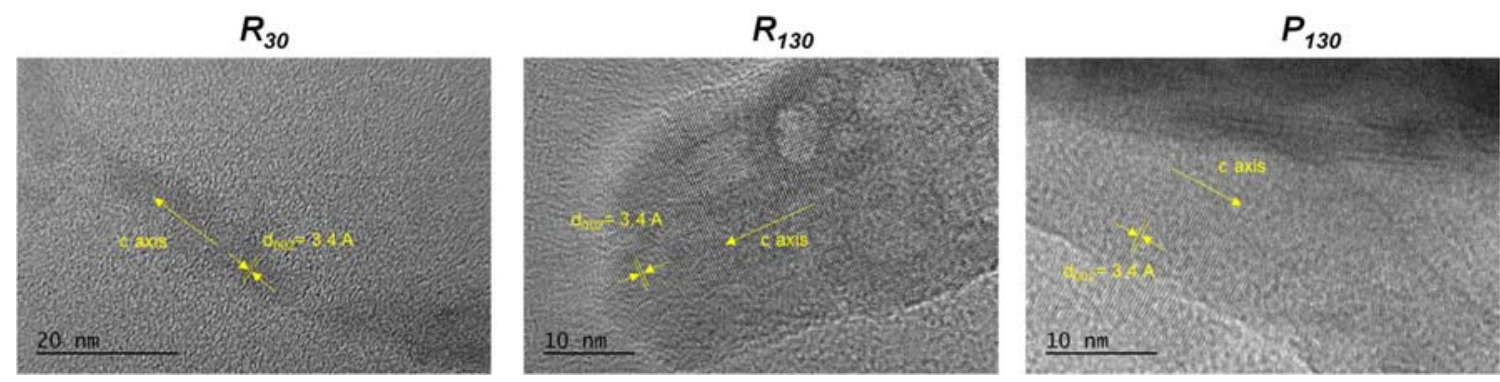

Figure S2. HRTEM micrographs of $R_{30}, R_{130}$ and $P_{130}$ NPs. The orientation of crystallographic planes, identified by inter-reticular distance measurements from the line profile (not shown), is consistent with the growth along the c-axis.

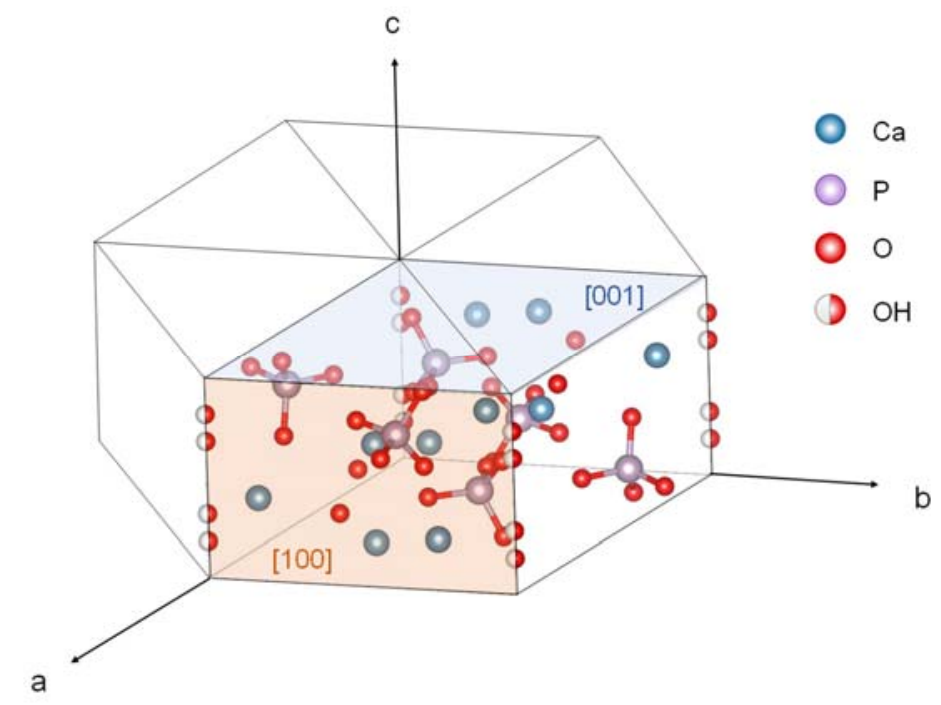

Figure S3. Schematic representation of the crystalline structure of Hap showing the [100] and [001] directions. 


\section{Raman}

Table S1. Raman shifts of different chemical moieties $\left(\mathrm{cm}^{-1}\right)$ referenced in the literature and assigned for Hap samples $\left(R_{30}, R_{130}\right.$ and $\left.P_{130}\right)$.

\begin{tabular}{lllll}
\hline Assignments & Literature[1-4] & $R_{30}$ & $R_{130}$ & $P_{130}$ \\
\hline $\mathrm{V}_{2} \mathrm{PO}_{4}{ }^{3-}$ & $433 / 448$ & $428 / 445$ & $428 / 445$ & $428 / 445$ \\
$\mathrm{~V}_{4} \mathrm{HPO}_{4}{ }^{2-}$ & $530-555$ & 522 & - & - \\
$\mathrm{V}_{4} \mathrm{PO}_{4}{ }^{3-}$ & $580 / 591 / 607$ & $580 / 590 / 607$ & $580 / 590 / 607$ & $580 / 590 / 607$ \\
$\mathrm{~V}_{1} \mathrm{HPO}_{4}{ }^{2-}$ & $875 / 961$ & $870 / 911$ & - & 870 \\
$\mathrm{~V}_{1} \mathrm{PO}_{4}{ }^{3-}$ & 964 & 962 & 962 & 962 \\
$\mathrm{~V}_{1} \mathrm{HPO}_{4}{ }^{2-}$ & 1005 & 1002 & 1002 & 1002 \\
$\mathrm{~V}_{3} \mathrm{PO}_{4}{ }^{3-}$ & $1048 / 1077$ & $1046 / 1075$ & $1046 / 1075$ & $1046 / 1075$ \\
$\mathrm{~V}_{3} \mathrm{HPO}_{4}{ }^{2-}$ & 1092 & 1114 & - & - \\
\hline
\end{tabular}




\section{Morphology of Hap NPs in aqueous solutions}
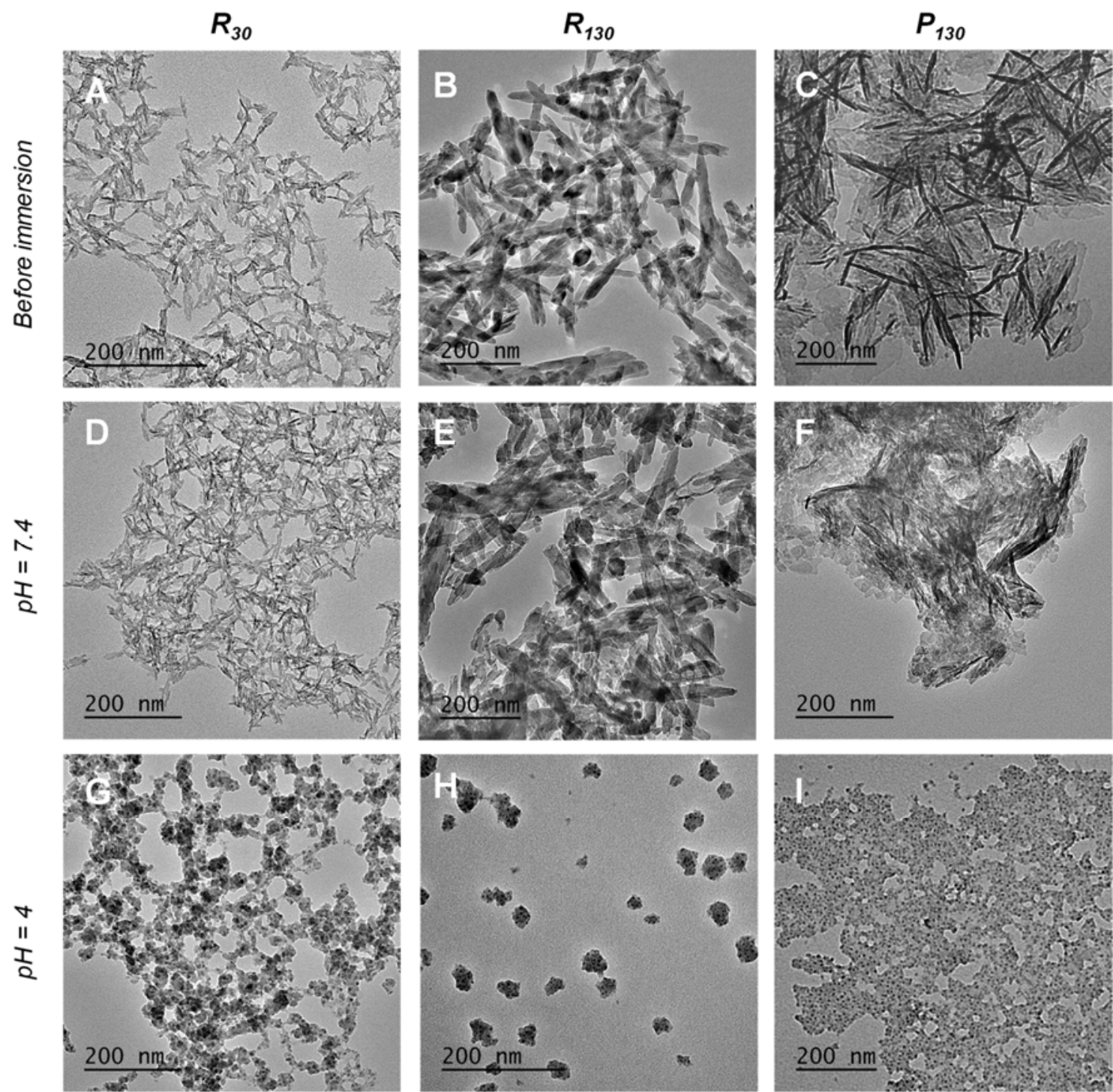

Figure S4. TEM micrographs of (A, D, G) $R_{30}$, (B, E, H) $R_{130}$ and (C, F, I) $P_{130}$ NPs (A-C) prior to and after incubation in water solution at (D-F) $\mathrm{pH} 7.4$ or (G-I) $\mathrm{pH} 4$. 


\section{Hap - Col interaction in solution}

A

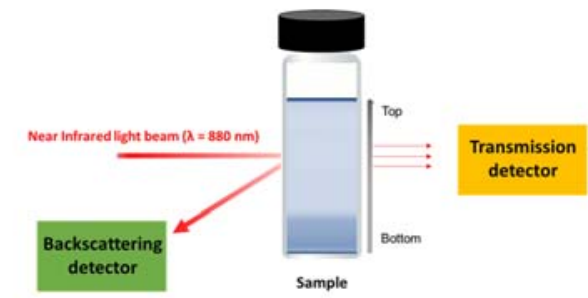

B

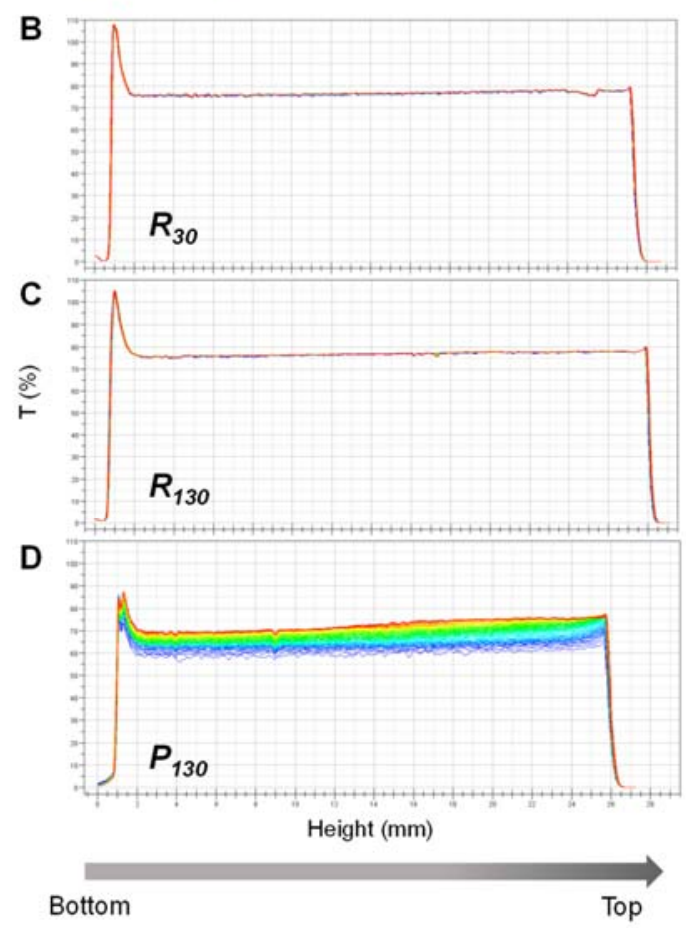

D
E

G

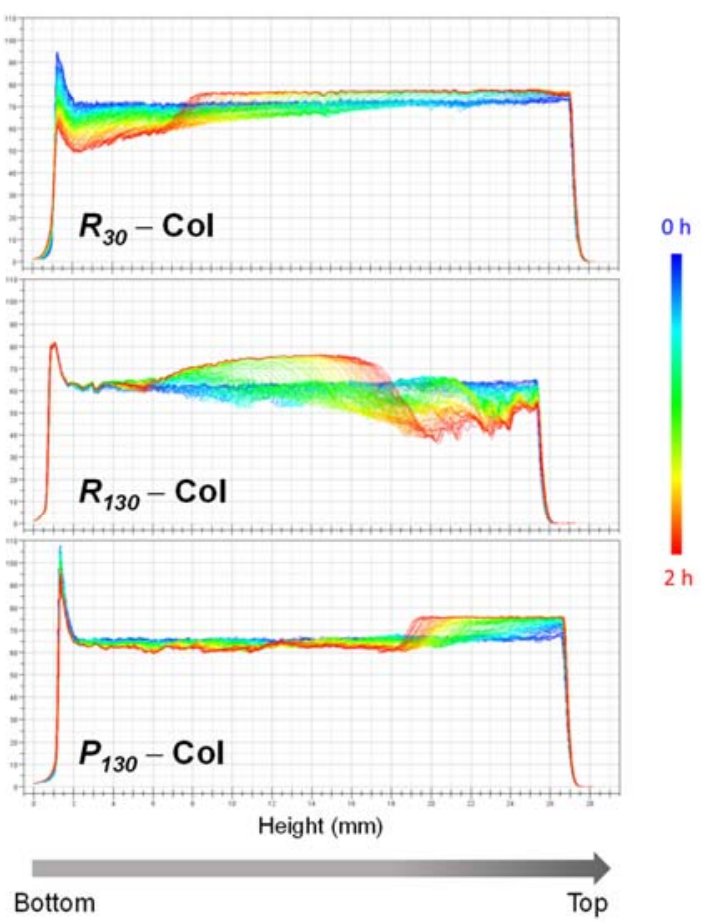

Figure S5. (A) Principle of time- and height-resolved turbidimetry technique; Transmission profiles of (B) $R_{30}$, (C) $R_{130}$, (D) $P_{130}$, (E) $R_{30}-\mathrm{Col}$, (F) $R_{130}-\mathrm{Col}$ and (G) $P_{130}-\mathrm{Col}$ systems. Only transmission signal is represented as $\mathrm{T}>0.2 \%$. 

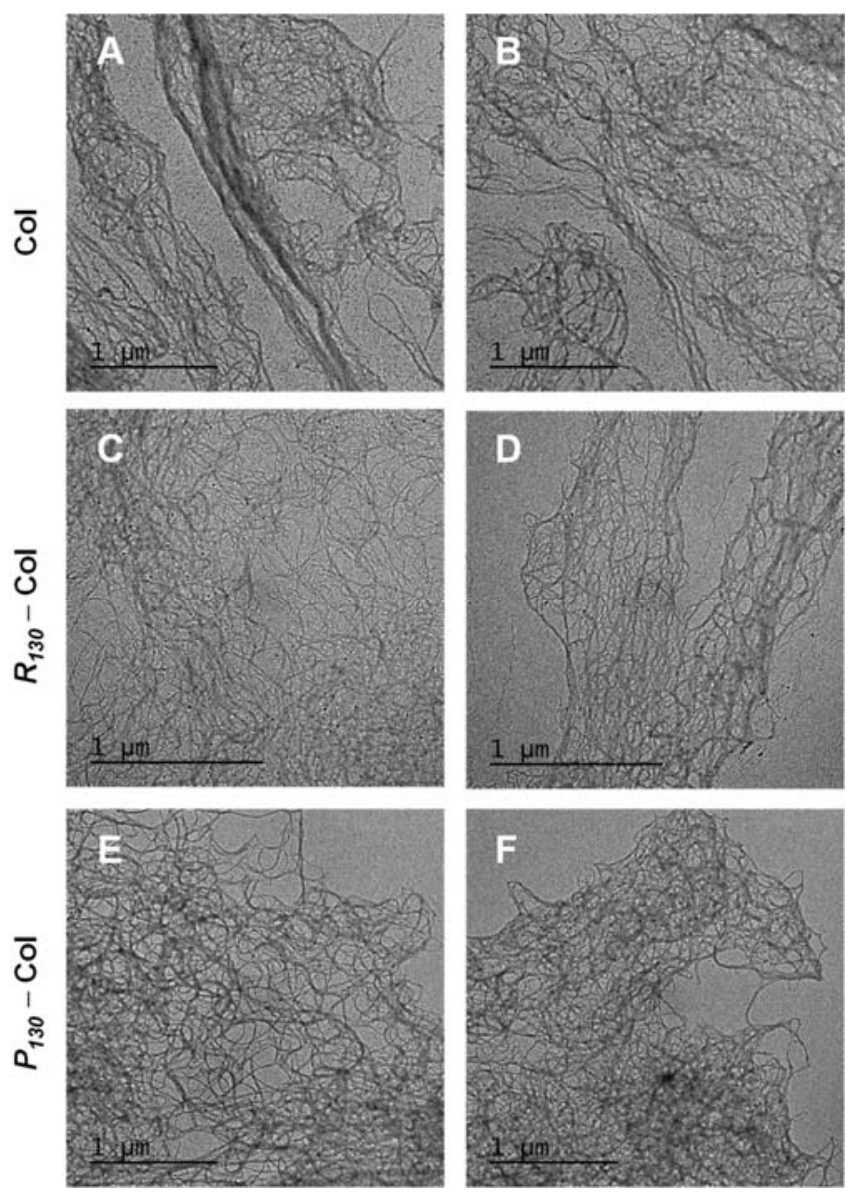

Figure S6. Typical TEM micrographs showing (A, B) Col, (C, D) $R_{130}-\mathrm{Col}$ and (E, F) $P_{130}-\mathrm{Col}$ systems in water at $\mathrm{pH}$ 7.4. A sample was taken from the middle of the tube ( $1 \mathrm{~h}$ after the addition of collagen to the Hap suspension), then deposited on the carbon-coated copper mesh grid and allowed to air-dry.
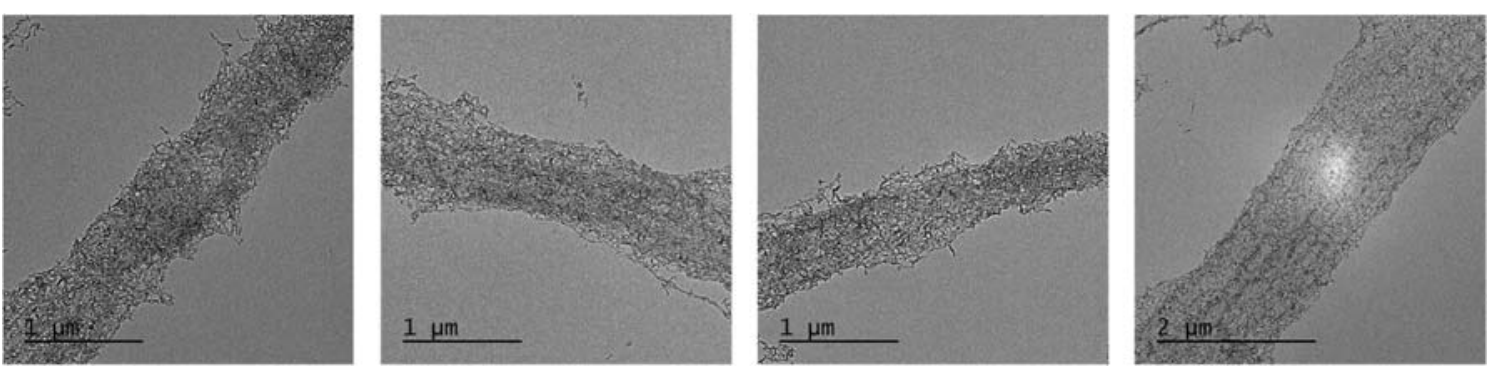

Figure S7. Typical TEM micrographs showing $R_{30}-\mathrm{Col}$ composite in water at $\mathrm{pH}$ 7.4. A sample was taken from the middle of the tube containing Col and Hap NPs ( $1 \mathrm{~h}$ after the addition of collagen to the Hap suspension), then deposited on the carbon-coated copper mesh grid and allowed to air-dry. The concentration of Hap and Col is 100 $\mu \mathrm{g} / \mathrm{mL}$ each. 


\section{LbL assembly of collagen-based multilayers}
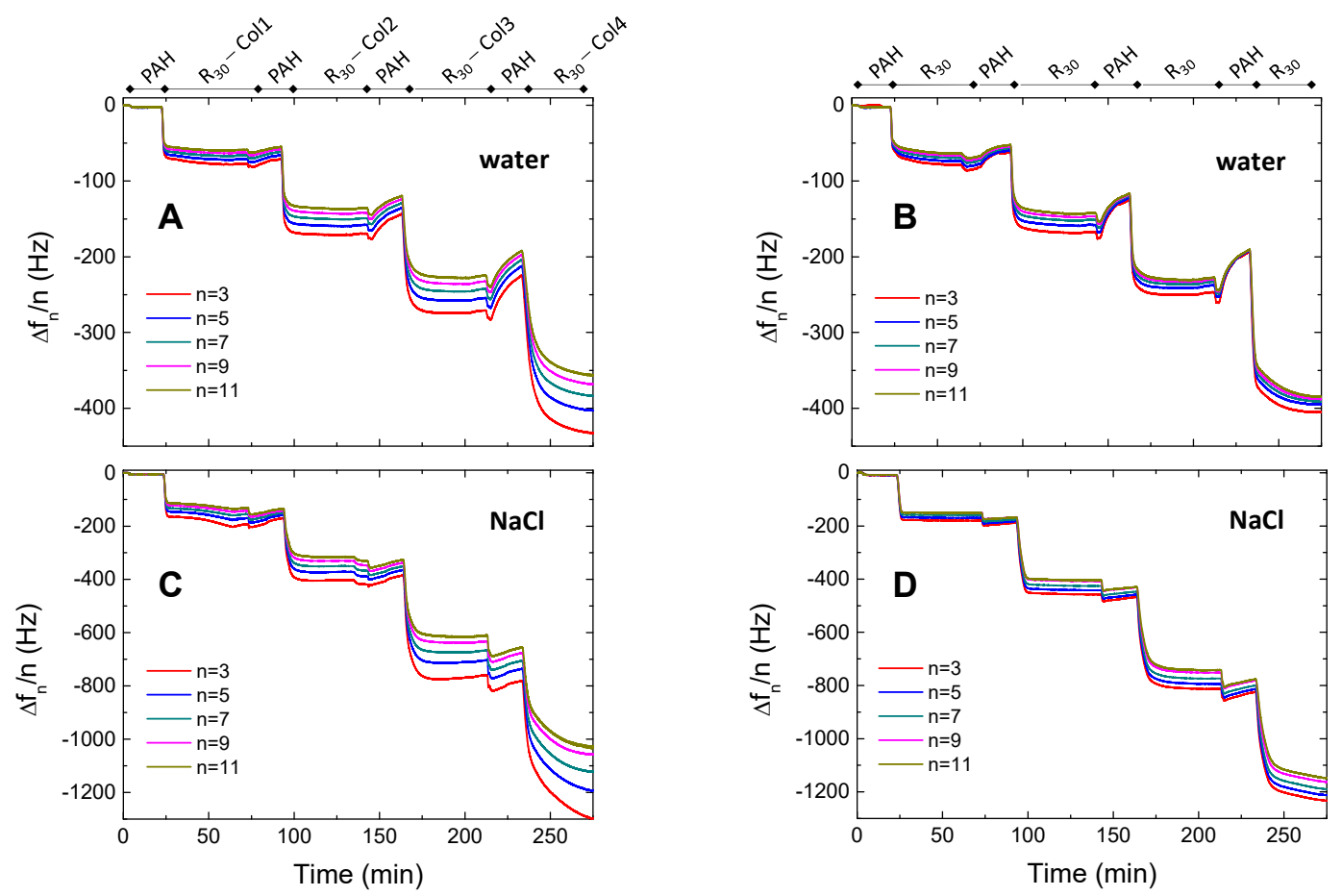

Figure S8. QCM-D measurements showing frequency changes in the $3^{\text {rd }}, 5^{\text {th }}, 7^{\text {th }}, 9^{\text {th }}$ and $11^{\text {th }}$ overtones during the build-up of $(\mathrm{A}, \mathrm{C})\left(\mathrm{PAH} / R_{30}-\mathrm{Col}\right)_{\mathrm{n}}$ and $(\mathrm{B}, \mathrm{D})\left(\mathrm{PAH} / R_{30}\right)_{\mathrm{n}}$ multilayers in $(\mathrm{A}, \mathrm{B})$ water $(\mathrm{pH} 7.4)$ or $(\mathrm{C}, \mathrm{D}) \mathrm{NaCl}$ solution (150 mM, pH 7.4). 

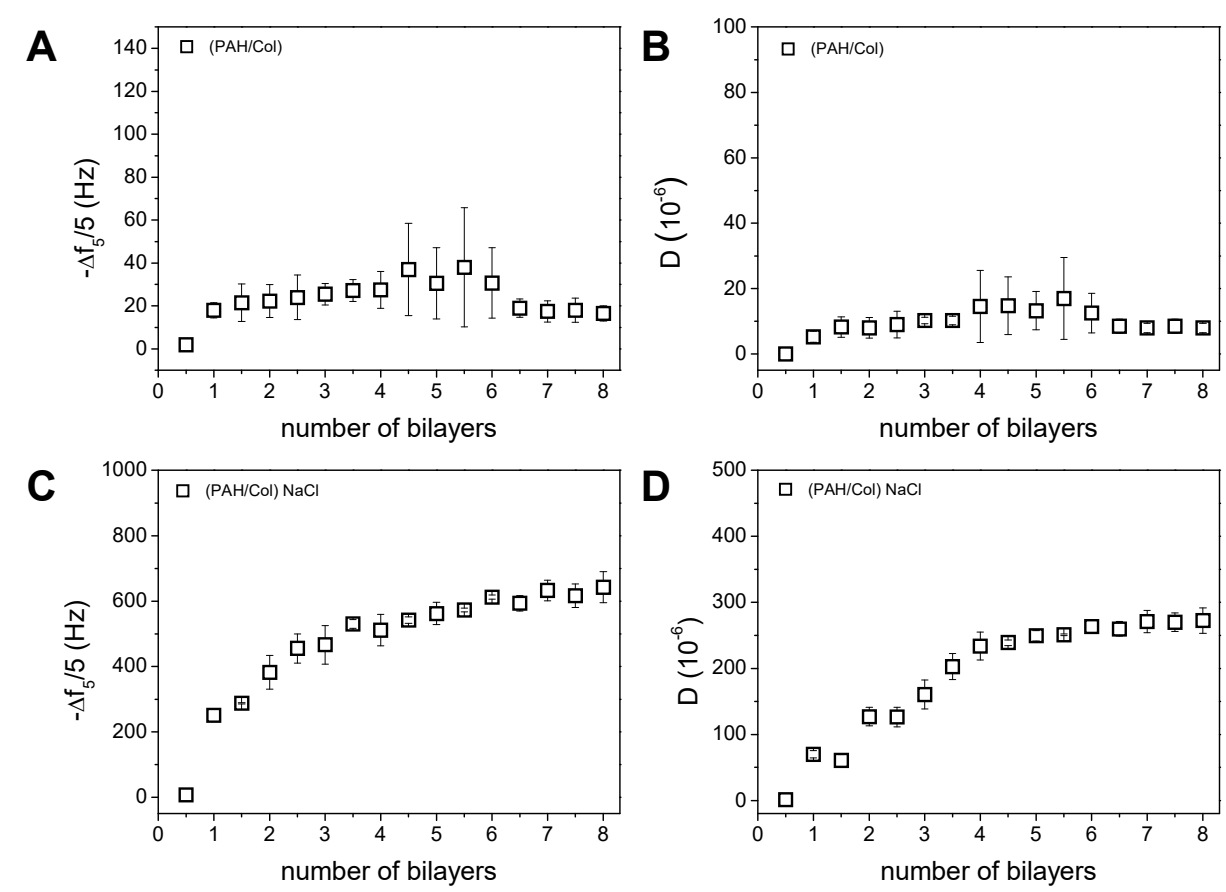

Figure S9. Evolution of the frequency shift, taken at the $5^{\text {th }}$ overtone, and the corresponding dissipation signal as a function of the number of bilayers $\mathrm{n}$, upon the build-up of $(\mathrm{PAH} / \mathrm{Col})_{\mathrm{n}}$ multilayers in $(\mathrm{A}, \mathrm{B})$ water $(\mathrm{pH} 7.4)$ or in (C, D) $\mathrm{NaCl}$ solution (150 mM, pH 7.4). 


\section{LbL assembly without renewing Hap - Col suspension}
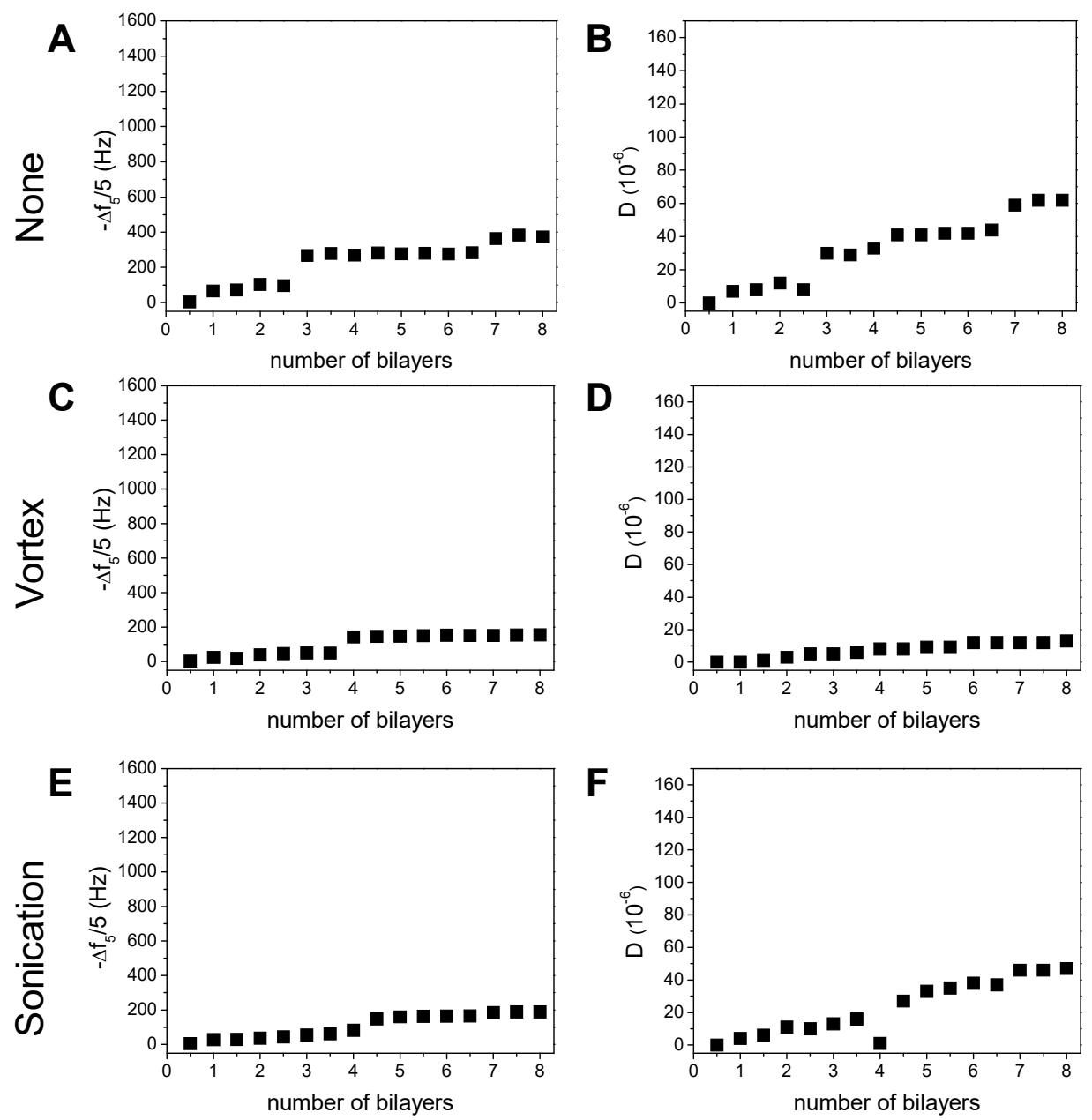

Figure S10. Evolution of the frequency shift, taken at the $5^{\text {th }}$ overtone, as a function of the number of bilayers $n$, upon the build-up of $\left(\mathrm{PAH} / R_{30}-\mathrm{Col}\right)_{\mathrm{n}}$ system in water at $\mathrm{pH} 7.4$ keeping the same solution at each bilayer (A) without stirring, (C) with vortexing the solution or (E) with sonicating the solution between each bilayer deposition; ( $\mathrm{B}, \mathrm{D}$ and $\mathrm{F}$ ) evolution of the corresponding dissipation signal as a function of the number of bilayers. 


\section{Hap - Col composite in $\mathrm{NaCl}$ solution}
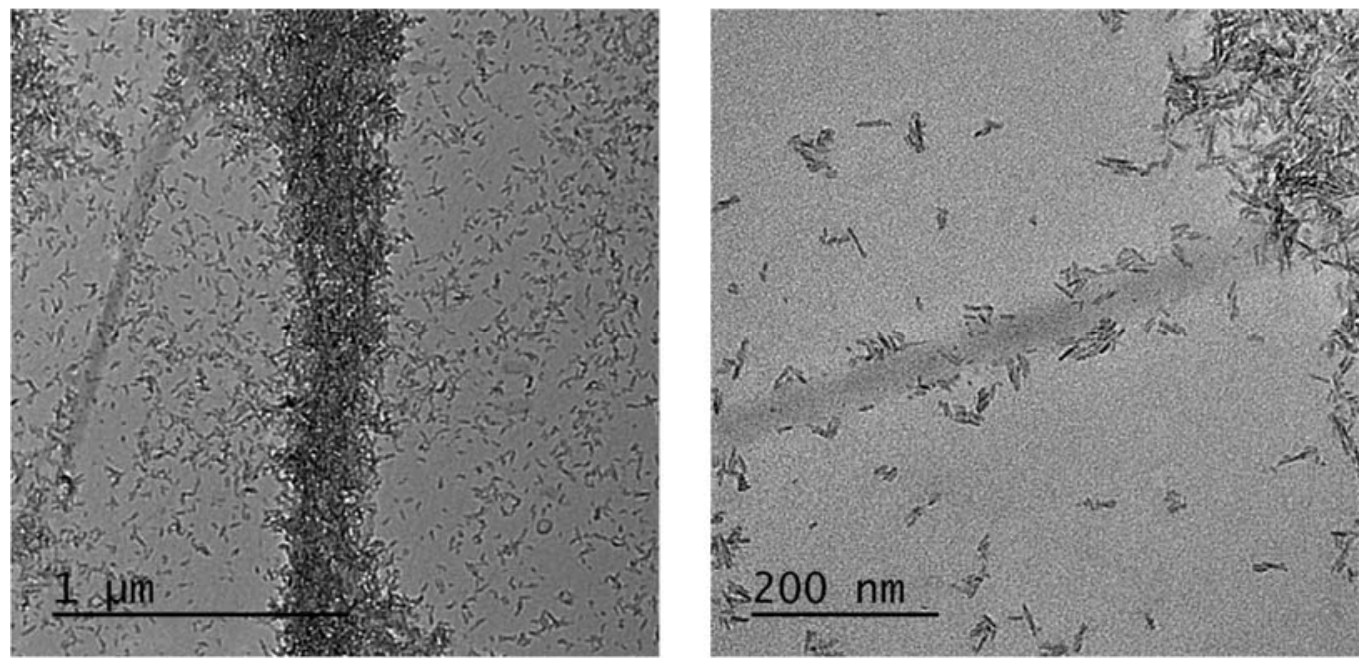

Figure S11. Typical TEM micrographs showing $R_{30}-\mathrm{Col}$ composite in $150 \mathrm{mM} \mathrm{NaCl}$ at $\mathrm{pH}$ 7.4: both coated and uncoated fibrils are observed with a large amount of "free" Hap NPs. A sample was taken from the middle of the cell containing Col and Hap NPs ( $1 \mathrm{~h}$ after the addition of collagen to the Hap suspension), then deposited on the carbon-coated copper mesh grid and allowed to air-dry. The concentration of Hap and Col is $100 \mu \mathrm{g} / \mathrm{mL}$ each. 


\section{References}

[1] A. Antonakos, E. Liarokapis, T. Leventouri, Micro-Raman and FTIR studies of synthetic and natural apatites, Biomaterials. 28 (2007) 3043-3054.

[2] G. Penel, G. Leroy, C. Rey, E. Bres, MicroRaman Spectral Study of the PO 4 and CO 3 Vibrational Modes in Synthetic and Biological Apatites, Calcif. Tissue Int. 63 (1998) $475-481$.

[3] J. Tao, K.C. Battle, H. Pan, E.A. Salter, Y.-C. Chien, A. Wierzbicki, J.J. De Yoreo, Energetic basis for the molecular-scale organization of bone, Proc. Natl. Acad. Sci. 112 (2015) 326-331.

[4] S. Koutsopoulos, Synthesis and characterization of hydroxyapatite crystals: A review study on the analytical methods, J. Biomed. Mater. Res. 62 (2002) 600-612. 